\title{
Rapamycin provides a therapeutic option through inhibition of mTOR signaling in chronic myelogenous leukemia
}

\author{
JIE LI $^{1,2}$, LIYING XUE ${ }^{3}$, HONGLING HAO $^{2}$, YUXIANG HAN $^{1}$, JINGCI YANG $^{1}$ and JIANMIN LUO ${ }^{1}$ \\ ${ }^{1}$ Department of Hematology, the Second Hospital, Hebei Medical University; ${ }^{2}$ Department of Hematology, Hebei General \\ Hospital, Shijiazhuang 050000; ${ }^{3}$ Laboratory of Pathology, Hebei Medical University, Shijiazhuang 050017, P.R. China
}

Received August 4, 2011; Accepted September 19, 2011

DOI: 10.3892/or.2011.1502

\begin{abstract}
Chronic myelogenous leukemia (CML) is a neoplasm of myeloid progenitor cells expressing Bcr-Abl fusion protein. However, some patients with CML are less likely to respond to imatinib, the inhibitor of Bcr-Abl kinase. Recent studies showed that mTOR pathway can increase responses to imatinib. The analysis of mTOR pathway in CML may provide new insights into possible targets of novel therapies. Therefore, we examined the expression of mTOR pathway molecules in bone marrow cells from CML patients and effect of rapamycin on K562 cells in vitro. Western blot analysis showed the visibly higher phosphorylation of mTOR (70.6\%), 4E-BP1 (76.5\%) and p70S6K (73.5\%) in bone marrow cells from CML patients. Moreover, treatment of CML cell line (K562) with rapamycin resulted in a decrease of phosphorylation of mTOR, 4E-BP1 and p70S6K. In vitro, the cell viability in groups with rapamycin treatment displayed a significant decrease in a dose-dependent manner by MTT. The data presented an increase of $G_{0} / G_{1}$ phase cells and decrease of $\mathrm{S}$ phase cells after rapamycin treatment, and the decreased expression of cyclinD1, higher expression of p21 at mRNA level was also detected in K562 with rapamycin. Treatment with $20 \mathrm{nmol} / 1$ or more rapamycin could increase apoptotic cells, decrease expression of bcl-2 and activate caspase-3. In conclusion, the mTOR pathway might be involved in chronic myelogenous leukemia. Inhibition of mTOR pathway could interfer with cell proliferation and increase cell apoptosis in K562 cells. It suggested that mTOR might be an important therapeutic target for myelogenous leukemia.
\end{abstract}

\section{Introduction}

Chronic myelogenous leukemia (CML) is a neoplasm of myeloid progenitor cells expressing 210-kDa Bcr-Abl fusion protein. The inhibitor of Bcr-Abl kinase, imatinib, has a remarkable clinical response in chronic phase of the majority

Correspondence to: Dr Jianmin Luo, Department of Hematology, the Second Hospital, Hebei Medical University, Shijiazhuang 050000, P.R. China

E-mail: luojm2011@163.com

Key words: chronic myelogenous leukemia, mTOR, p70S6K, 4E-BP1 of patients $(1,2)$. However, some patients with CML are less likely to respond to imatinib, and then develop imatinib resistance (3). Recent studies showed that signaling pathways, especially the mammalian target of rapamycin (mTOR) pathway, can increase responses to imatinib and overcome its resistance (4). Studies reported that mTOR and its downstream effectors could be activated in cell lines expressing Bcr-Abl in a Bcr-Abl kinase-dependent manner (5-7).

mTOR is a serine/threonine kinase that plays an important role within the PI3K/AKT/mTOR signaling pathway (8). The two major substrates of mTOR are ribosomal protein S6 kinase (p70S6K) and eukaryotic initiation factor 4E-binding protein 1 (4E-BP1), which regulates cap-dependent transcription and translation of a great number of proteins by phosphorylation. Studies have indicated that the molecules of mTOR pathway were concerned with tumorigenesis and mTOR inhibitors (rapamycin and RAD001) could affect sensitivity of tumors (including leukemias) to various forms of therapy (9-13). The result of the recent studies also indicated that the signaling pathway of mTOR became an important therapeutic target for leukemias $(14,15)$. However, understanding of the role of mTOR pathway in tumorigenesis and the impact of rapamycin in clinic treatment of myelogenous leukemia is unclear, and more studies need to be done.

Therefore, we examined expression of mTOR and its downstream molecules (p70S6K and 4E-BP1) in bone marrow cells from patients with chronic myelogenous leukemia. In addition, we investigated cell growth, apoptosis and expression of mTOR pathway molecules in cell line of K562 after rapamycin treatment.

\section{Materials and methods}

Patients. Thirty-four cases of CML treated at the Second Hospital, Hebei Medical University were included in this study from June 2009 to December 2010. Among them, there were 23 cases of male and 11 cases of female, and the median age (range) of 34 cases were 54 years (33-65). Ten healthy donors were collected as control group. After informed consent was obtained from all subjects, mononuclear cells were collected by bone marrow aspiration.

Cell culture and treatment. Chronic myelogenous leukemia cell line K562 was purchased from Beijing Institute for Cancer 
Research. The cells were cultured in RPMI-1640 supplemented with $100 \mathrm{U} / \mathrm{ml}$ penicillin, $100 \mathrm{U} / \mathrm{ml}$ streptomycin, and $10 \%$ fetal bovine serum (FBS). Rapamycin was diluted in DMSO and the groups of cells were treated with solvent with various concentrations of rapamycin.

MTT assay. MTT evaluated the level of proliferation. Cells were seeded on 96-well culture plates and treated with rapamycin ranging from 1 to $1000 \mathrm{nmol} / 1$ for $24 \mathrm{~h}$ at $37^{\circ} \mathrm{C}$. After adding $20 \mu \mathrm{l}$ of MTT stock solution to each well (final concentration: $0.5 \mathrm{mg} / \mathrm{ml}$ ), cells were incubated for $4 \mathrm{~h}$. After correction for background absorbance, cell viability was assayed compared to control wells. The sensitivity of cells to rapamycin was measured by $\mathrm{IC}_{50}\left(\mathrm{IC}_{50}\right.$ values defined as the concentration inducing $50 \%$ loss of cell viability).

Flow cytometry (FCM) assay. Cells were cultured as described above and treated with different concentrations of rapamycin $(0,20,40$ and $80 \mathrm{nmol} / \mathrm{l})$ for 24 or $48 \mathrm{~h}$, then washed with PBS and harvested in the buffer (PBS- $0.05 \%$ trypsin). Apoptosis of K562 cells in different groups were determined by Annexin V/PI apoptosis detection kit (MultiSciences Biotechnology, Hangzhou, China) according to manufacturer's protocol. This test discriminates intact cells (Annexin V-/ $\mathrm{PI}^{-}$), early apoptotic cells (Annexin $\mathrm{V}^{+} / \mathrm{PI}^{-}$) and late apoptotic/ necrotic cells (Annexin $\mathrm{V}^{+} / \mathrm{PI}^{+}$).

Protein extraction and measurement. Mononuclear cells from bone marrow cells of CML patients and harvested K562 cells with rapamycin treatment $(20,40$ and $80 \mathrm{nmol} / \mathrm{l})$ were washed with ice-cold PBS. Total protein was extracted using a lysis buffer containing $1 \%$ Triton X-100, $150 \mathrm{mmol} / \mathrm{l} \mathrm{NaCl}$, $2 \mathrm{mmol} / \mathrm{l} \mathrm{EDTA}, 1 \mathrm{mmol} / \mathrm{l}$ sodium fluoride, $1 \mathrm{mmol} / \mathrm{l}$ sodium orthovanadate, $1 \mathrm{mmol} / \mathrm{l}$ phenylmethylsulfonyl fluoride, $2 \mathrm{mg} /$ $\mathrm{ml}$ aprotinin and $0.5 \mathrm{mmol} / \mathrm{l} \mathrm{DTT}$. After lysates were cleared by centrifugation $(12,000 \mathrm{rpm})$ for $30 \mathrm{~min}$, protein concentration was measured using a standard Coomassie brilliant blue (CBB) total protein assay kit (Jiancheng Bioengineering, Nanjing, China).

Western blot analysis. Protein samples were run on a 7.5\%$15 \%$ SDS-PAGE gel and transferred to PVDF membrane. After blocking non-specific binding sites with $5 \%$ non-fat milk in TBS-T $(20 \mathrm{mmol} / 1$ Tris-HCl, pH 7.4, $150 \mathrm{mmol} / 1 \mathrm{NaCl}, 0.1 \%$ Tween-20) for $60 \mathrm{~min}$, the membranes were incubated overnight at $4{ }^{\circ} \mathrm{C}$ with primary antibody (mTOR, p-mTOR, 4E-BP1, p-4EBP1, p70S6K and p-p70S6K; Cell Singaling, USA. bcl-2 and caspase-3, Santa Cruz, CA). Then the membranes were probed with HRP-conjugated secondary antibody (at 1:5,000 dilution) for $60 \mathrm{~min}$ at $37^{\circ} \mathrm{C}$. After being washed 3 times with TTBS, the membranes were developed by ECL chemiluminescent detection system.

Reverse transcription PCR (RT-PCR) analysis. K562 cells treated with rapamycin $(20,40$ and $80 \mathrm{nmol} / \mathrm{l})$ were harvested. Total RNA was extracted using TRIzol Reagent (Invitrogen, USA) according to the manufacturer's instructions. After cDNA being obtained by reverse transcription (Promega, USA), PCR was performed with gene-specific primers. The fragment of GAPDH cDNA gene was used as an internal control (Table I).
Table I. Primers for RT-PCR amplification.

\begin{tabular}{lcc}
\hline Primers & Sequence & Length \\
\hline mTOR & & \\
Sense & 5'-AGA GAG GAC ACA AGC AC-3' & \\
Antisense & 5'-CAC AGA TAA TGG CAA TG-3' & $155 \mathrm{bp}$
\end{tabular}

$4 \mathrm{E}-\mathrm{BP} 1$

Sense 5'-GGG GAC TAC AGC ACG AC-3'

Antisense 5'-CGC CCG CTT ATC TTC T-3'

228 bp

p70S6K

Sense 5'-TAC TTC GGG TAC TTG GTA A-3'

Antisense 5'-GAT GAA GGG ATG CTT TAC T-3'

$188 \mathrm{bp}$

cyclinD1

Sense 5'-CCC ACT CCT ACG ATA CGC-3'

Antisense 5'-TCG TCC TGA AAC TCC GTT-3'

$332 \mathrm{bp}$

p21

Sense 5'-GCG CCA TGT CAG AAC CGG CTG-3'

Antisense 5'-TCC TCC CAA CTC ATC CCG GCC-3' 277 bp

cyclinB1

Sense 5'-TTG GTT GAT ACT GCC TC-3'

Antisense 5'-TGG TCT GAC TGC TTG CT-3'

$207 \mathrm{bp}$

GAPDH

Sense 5'-GGA AGG TGA AGG TCG GAG T-3'

Antisense 5'-CCT GGA AGA TGG TGA TGG G-3' 231 bp

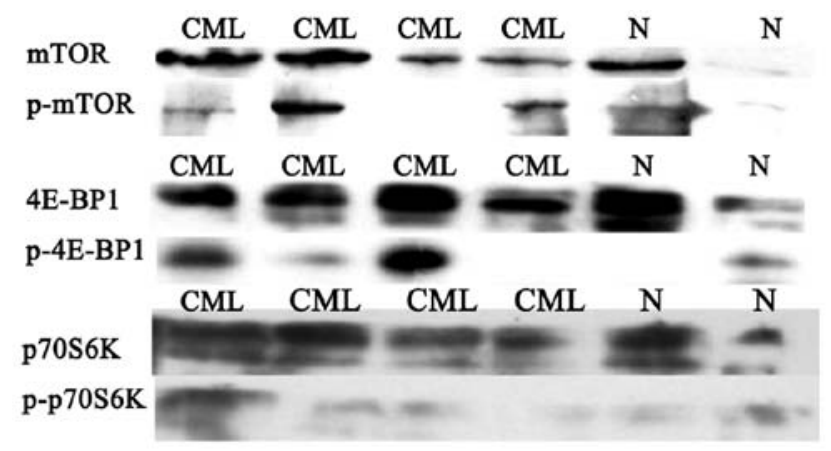

Figure 1. Expression of mTOR signaling proteins in chronic myelogenous leukemia. The band seen by chemiluminescent detection system represents expression, and no band represents no expression. CML, chronic myelogenous leukemia; $\mathrm{N}$, normal bone marrow.

The $25 \mu 1$ PCR reaction mixes contained $5 \mu 1$ of $5 \mathrm{X}$ Reaction Buffer (Promega, USA), $0.35 \mu 1$ of $10 \mathrm{mmol} / \mathrm{l} \mathrm{dNTP}$, $2.5 \mathrm{pm}$ forward and reverse primers, $0.15 \mu \mathrm{l}$ GoTaq DNA Polymerase (Promega, USA) and $1.5 \mu \mathrm{l}$ cDNA. The reaction was initiated at $94^{\circ} \mathrm{C}$ for $5 \mathrm{~min}$, and then performed using the following amplification cycles: denaturation at $94^{\circ} \mathrm{C}$ for $50 \mathrm{sec}$, annealing at $55^{\circ} \mathrm{C}$ for $30 \mathrm{sec}$, and extension at $72^{\circ} \mathrm{C}$ for $30 \mathrm{sec}$. The number of amplification cycles was estimated by a preliminary study to optimize the exponential phase of PCR. The final cycle at $72^{\circ} \mathrm{C}$ for $10 \mathrm{~min}$ was also included. PCR products were visualized by gel electrophoresis on $1.5 \%$ agarose (w/v) 
Table II. Expression of mTOR signaling proteins in chronic myelogenous leukemia.

\begin{tabular}{lcrlrr}
\hline \multirow{2}{*}{ Group } & \multicolumn{2}{c}{ Normal bone marrow $(10)$} & & \multicolumn{2}{c}{ Chronic myelogenous leukemia (34) } \\
\cline { 2 - 3 } \cline { 5 - 6 } & \multicolumn{1}{c}{+} & & & + & - \\
\hline mTOR & $6(60.0 \%)$ & $4(40.0 \%)$ & & $28(82.4 \%)$ & $6(17.6 \%)$ \\
Phosphor-mTOR & $3(30.0 \%)$ & $7(70.0 \%)$ & & $24(70.6 \%)^{\mathrm{a}}$ & $10(29.4 \%)$ \\
4E-BP1 & $8(80.0 \%)$ & $2(20.0 \%)$ & & $30(88.2 \%)$ & $4(11.8 \%)$ \\
Phosphor-4E-BP1 & $4(40.0 \%)$ & $6(60.0 \%)$ & & $26(76.5 \%)^{\mathrm{a}}$ & $8(23.5 \%)$ \\
p70S6K & $7(70.0 \%)$ & $3(30.0 \%)$ & & $29(85.3 \%)$ & $5(14.7 \%)$ \\
Phosphor-p70S6K & $2(20.0 \%)$ & $8(80.0 \%)$ & & $25(73.5 \%)^{\mathrm{a}}$ & $9(26.5 \%)$ \\
\hline
\end{tabular}

Statistical analysis was based on $\chi^{2}$ test. ${ }^{\text {a }} \mathrm{P}<0.05$, compared with normal bone marrow.

\section{A}
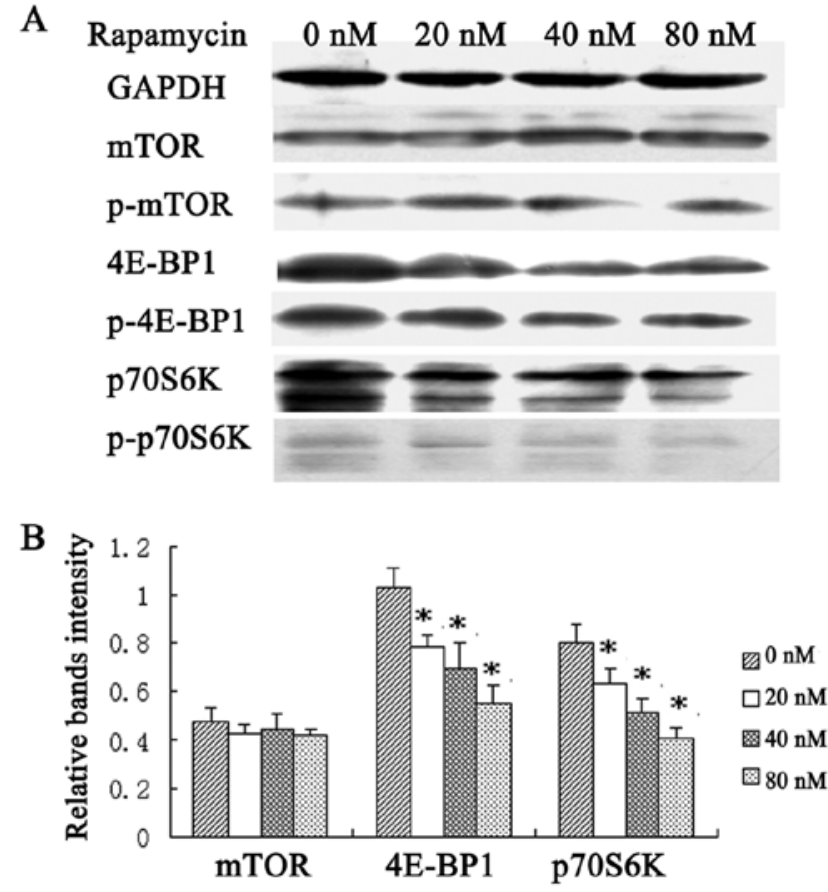

Figure 2. Effect of rapamycin on mTOR, 4E-BP1 and p70S6K in K562 cells. (A) Expression of the molecules and its phosphorylation, and (B) expression of the molecules at mRNA level. ${ }^{*} \mathrm{P}<0.05$, compared with solvent control group.

gel, and then viewed using the ultraviolet photometry (UVP) bioimaging system.

Statistical analysis. Values are presented as means \pm standard deviation (SD). Statistical differences were performed with one-way analysis of variance (ANOVA) by the statistical software of SPSS 13.0 for Windows (SPSS, Chicago, IL). The clinical variables were analyzed by the $\chi^{2}$ test and Fisher's exact test. $\mathrm{P}<0.05$ was considered statistically significant.

\section{Results}

Expression of mTOR signaling molecules in bone marrow cells with CML. The phosphorylation status of mTOR, 4E-BP1 and p70S6K was detected in 34 patients with CML.

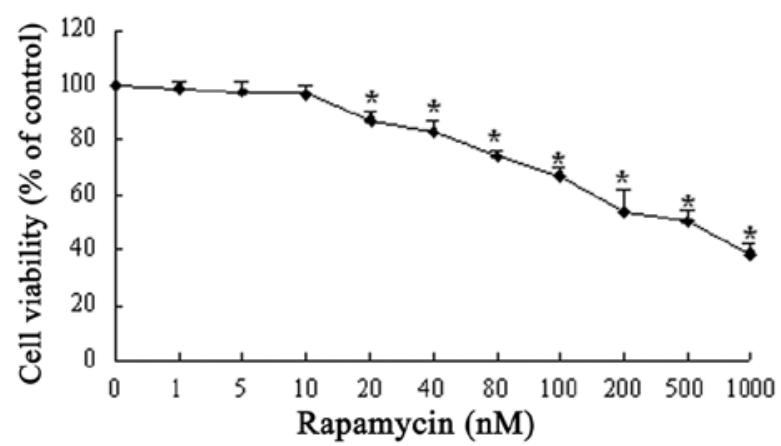

Figure 3. Effect of Rapamycin on K562 cells. Cell viability was determined after exposure to rapamycin ranging from 5 to $1000 \mathrm{nmol} / \mathrm{l}$ for $24 \mathrm{~h}$. Control value was taken as $100 \%$. Data represent the mean \pm SD. ${ }^{*} \mathrm{P}<0.05$, compared with solvent control group.

We also determined the expression of total 4E-BP1 and p70S6K in these cases. p-mTOR was examined in 24 of 34 (70.6\%), higher than that in normal bone marrow cells. Moreover, the phosphorylation of 4E-BP1 and p70S6K was more detected in CML patients (Table II, Fig. 1). Moreover, p-4E-BP1 was determined in 26 of 27 cases with positive expression of total 4E-BP1 $(96.3 \%)$, significantly higher than in normal bone marrow (4/8, $50 \%, \mathrm{P}<0.05)$. In 29 cases of CML with expression of total p70S6K, 25 (86.2\%) cases showed phosphorylation, and only 2 $(28.6 \%)$ cases showed p-p70S6K expression in 7 cases of normal bone marrow with total p70S6K expression $(\mathrm{P}<0.05)$. We found that mTOR signaling is frequently activated in CML.

Rapamycin decreased phosphorylation of mTOR and downstream molecules in $K 562$ cells. The effect of rapamycin on mTOR and its downstream molecules by Western blot and RT-PCR was shown in Fig. 2. The expression of mTOR displayed no significant variation between groups of K562 cells with rapamycin and solvent treatment $(\mathrm{P}>0.05)$. Nevertheless, the phosphorylation of mTOR was significantly decreased in groups with rapamycin treatment than that in solvent group $(\mathrm{P}<0.05$, Fig. 2A). Thus, these data indicate that rapamycin inhibits phosphorylation of mTOR.

To further explore the mechanism of mTOR and its substrates, we examined the expression of 4E-BP1 and p70S6K. The significantly lower expression of 4E-BP1 and p70S6K 

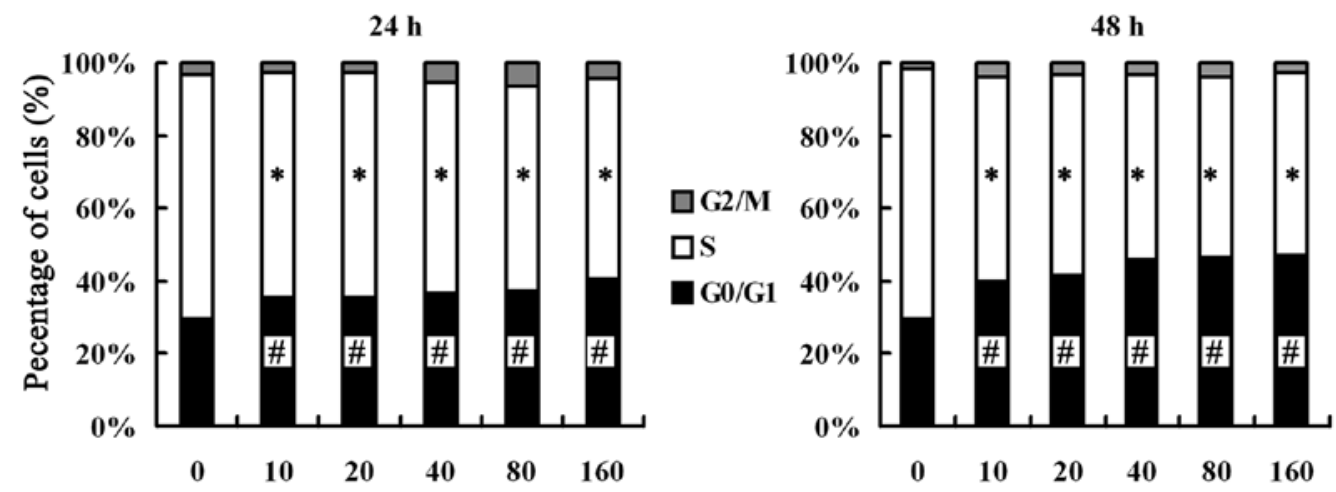

Rapamycin (nM)

\begin{tabular}{|c|c|c|c|c|c|c|c|}
\hline \multicolumn{2}{|c|}{} & $0 \mathrm{nM}$ & $10 \mathrm{nM}$ & $20 \mathrm{nM}$ & $40 \mathrm{nM}$ & $80 \mathrm{nM}$ & $160 \mathrm{nM}$ \\
\hline \multirow{3}{*}{$24 \mathrm{~h}$} & & $29.56 \pm 2.89$ & $35.38 \pm 2.18$ & $35.7 \pm 3.65$ & $36.73 \pm 3.83$ & $37.17 \pm 2.6$ & $40.21 \pm 3.16$ \\
\cline { 2 - 8 } & & $67.25 \pm 2.55$ & $62.01 \pm 2.77$ & $61.33 \pm 3.18$ & $57.71 \pm 2.79$ & $56.26 \pm 3.64$ & $55.15 \pm 3.48$ \\
\cline { 2 - 8 } & {[} & $3.19 \pm 0.87$ & $2.61 \pm 0.75$ & $2.97 \pm 0.73$ & $5.56 \pm 1.21$ & $6.57 \pm 1.18$ & $4.63 \pm 1.2$ \\
\hline \multirow{3}{*}{$48 \mathrm{~h}$} & & $29.75 \pm 1.86$ & $39.75 \pm 2.44$ & $41.59 \pm 3.07$ & $45.64 \pm 3.69$ & $46.28 \pm 3.87$ & $46.89 \pm 3.48$ \\
\cline { 2 - 8 } & & $68.66 \pm 1.86$ & $56.52 \pm 1.68$ & $55.07 \pm 3.26$ & $51.17 \pm 2.42$ & $50.09 \pm 2.23$ & $50.62 \pm 2.76$ \\
\cline { 2 - 8 } & 0 & $1.60 \pm 0.34$ & $3.73 \pm 0.76$ & $3.34 \pm 0.66$ & $3.19 \pm 1.32$ & $3.63 \pm 1.87$ & $2.49 \pm 0.73$ \\
\hline
\end{tabular}

Figure 4. Rapamycin arrests $\mathrm{K} 562$ cells at $\mathrm{G}_{0} / \mathrm{G}_{1}$ phase. Cell cycle was detected by flow cytometry. $\mathrm{G}_{0} / \mathrm{G}_{1}$ phase cells were increased after rapamycin treatment $\left({ }^{*} \mathrm{P}<0.05\right.$, compared with the solvent control group). Inversely, $\mathrm{S}$ phase cells were decreased following rapamycin treatment $($ " $\mathrm{P}<0.05$, compared with the solvent control group).

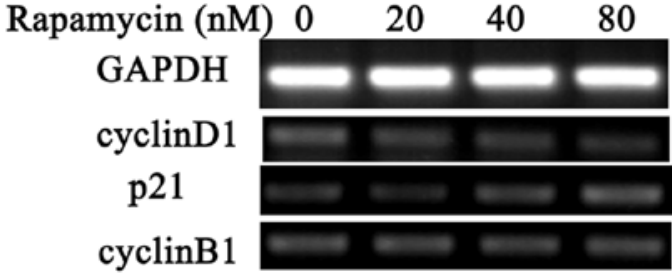

Figure 5. Expression of cell cycle regulators at mRNA level in K562 cells after rapamycin treatment. Rapamycin decreased cyclinD1 and increased p21 expression at mRNA level.

at mRNA level were seen in K562 cells after rapamycin treatment $(\mathrm{P}<0.05$, Fig. 2B). Moreover, Western blot data also showed coincident results with RT-PCR, especially the phosphorylations of 4E-BP1 and p70S6K were significantly decreased in groups of cells with rapamycin treatment than that in solvent group $(\mathrm{P}<0.05$, Fig. $2 \mathrm{~A})$. The findings confirmed that rapamycin inhibited phosphorylation of mTOR, and then had an effect on its substrates in K562 cells.

Rapamycin inhibited growth of K562 cells. Effect of rapamycin on K562 cells was measured by MTT assay after treatment. The cell viability in groups with rapamycin treatment displayed a significant decrease in a dose-dependent manner ranging from 5 to $1000 \mathrm{nmol} / \mathrm{l}(\mathrm{P}<0.05$, Fig. 3).

Rapamycin arrests $K 562$ cells at $G_{0} / G_{I}$ phase. Exponentially growing K562 cells were treated with rapamycin for 24 and $48 \mathrm{~h}$, and detected by flow cytometry. As shown in Fig. 4, after treated with rapamycin for $24 \mathrm{~h}$ the proportion of cells in $\mathrm{G}_{0} / \mathrm{G}_{1}$ phase in treated groups was significantly increased, compared with that in solvent control group $(29.56 \pm 2.89, \mathrm{P}<0.05)$. With
A
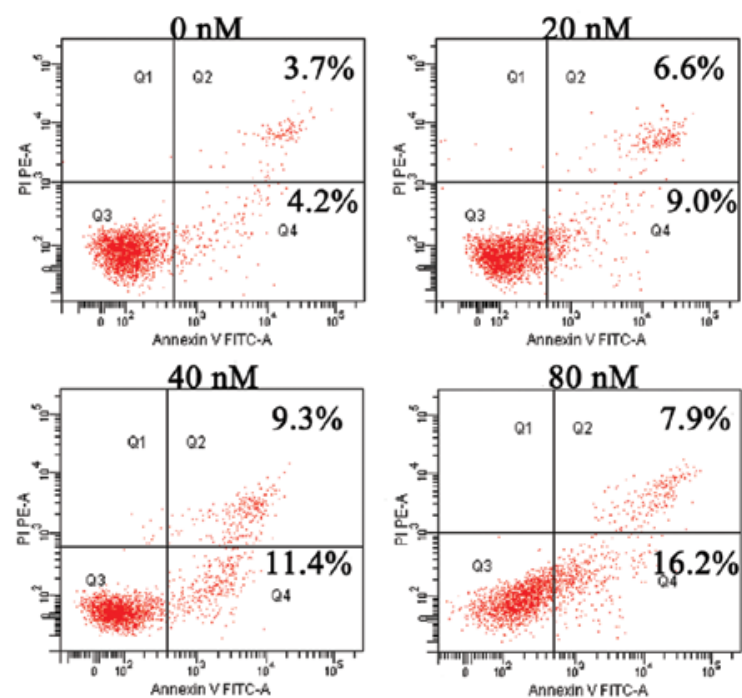

B

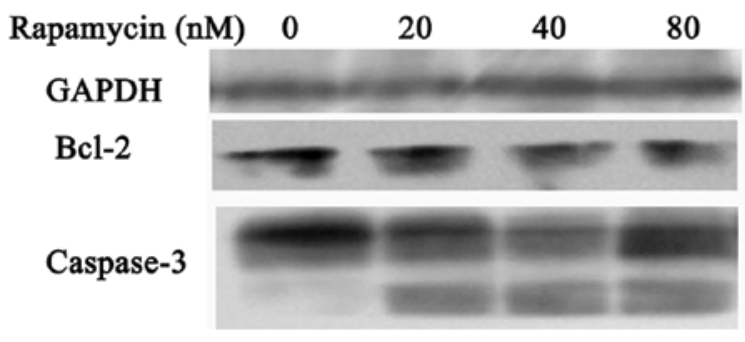

Figure 6. Rapamycin induced cell apoptosis of K562 cells. The total percentage of apoptotic cells was increased significantly in rapamycin treatment groups in (A) and (B) showed expression of apoptosis regulators.

regard to $\mathrm{S}$ phase cells, the decreased population was accompanied with the increase of $G_{0} / G_{1}$ phase cells. No difference was found in $G_{2} / M$ cell populations after treatment with 
rapamycin, as compared with the control group. Furthermore, the significant increase of $\mathrm{G}_{0} / \mathrm{G}_{1}$ phase cells and decrease of $\mathrm{S}$ phase cells were found in groups with rapamycin treatment for $48 \mathrm{~h}$, as well as the treated groups for $24 \mathrm{~h}$. The results indicated that rapamycin could induce K562 cells to arrest in $\mathrm{G}_{1}$ phase.

We also assessed expression of several cell cycle regulators at mRNA level after rapamycin treatment (Fig. 5). The expression of cyclinD1 mRNA was significantly decreased $(\mathrm{P}<0.05)$. On the contrary, higher expression of $\mathrm{p} 21$ at mRNA level was detected in cells with rapamycin treatment $(\mathrm{P}<0.05)$. Expression of cyclinB1 show no variety in K562 cells after rapamycin incubation.

Rapamycin induces apoptosis in K562 cells. To determine if rapamycin resulted in increased apoptosis of K562 cells, we studied apoptosis after treatment of rapamycin with increasing concentrations for $24 \mathrm{~h}$. As shown in Fig. 6A (Q1, damaged cells; Q2, late apoptotic cells; Q3, living cells; and Q4, early apoptotic cells), the percentage of apoptotic cells in treated groups with 20,40 and $80 \mathrm{nmol} / \mathrm{l}$ was $15.6,20.7$ and $24.1 \%$, respectively, significantly higher than in control group $(7.9 \%$, $\mathrm{P}<0.05)$. The result indicated that treatment with $20 \mathrm{nmol} / \mathrm{l}$ or higher concentrations of rapamycin increased apoptotic cells, including early and late apoptotic cells, in a concentrationdependent manner.

To study the underlying apoptotic mechanisms, expression of apoptosis regulators, caspase- 3 and bcl-2, were assessed after treatment with 20, 40 and $80 \mathrm{nmol} / 1$ rapamycin (Fig. 6B). There was decreased expression of bcl-2 after rapamycin treatment. Meanwhile, the caspase-3 activity ( $17 \mathrm{kD})$ was only detected in K562 cells in treated groups (Fig. 6B). Our findings confirmed that rapamycin induced apoptosis in K562 cells.

\section{Discussion}

PI3K/AKT/mTOR signaling pathway plays important roles in many cancers including various hematopoietic neoplasms. PI-3 kinase, induced by Bcr-Abl through a direct association with its regulatory subunit, could activate mTOR upon phosphorylation by Akt in cell line of CML (5). In addition, rapamycin, as the inhibitor of mTOR, was shown to combine with PI3K/PDK1 inhibitor (BAG956) in a non-antagonistic fashion against Bcr-Abl expressing cells (16). To understand the signaling pathway of mTOR, we measured expression of mTOR and its down-stream molecules in bone marrow cells with CML. Our results showed significantly higher expression of p-mTOR in bone marrow cells from patients, and phosphorylation of 4E-BP1 and p70S6K was also detected at high level in CML cases. It suggested that the mTOR pathway was activated in CML.

Previous data showed that PI3K/AKT/mTOR was a central regulatory pathway of protein translation involved in the regulation of cell proliferation, differentiation and survival $(17,18)$. mTOR activation ( $\mathrm{p}$-mTOR) could phosphorylate its downstream targets. Phosphorylated p70S6K had an effect on cell growth through inducing protein synthesis and cell survival (19). Moreover, activated p70S6K could increase the translation of 5'-terminal oligopyrimidine tract mRNAs (20). 4E-BP1 phosphorylation (Ser37; Thr46; Ser65; Thr70) leads to releasing the eukaryotic initiation factor $4 \mathrm{E}$ (eIF4E). eIF4E plays key roles in translation of 5' capped mRNAs, including transcripts encoding growth promoting molecules. Our study showed that 4E-BP1 and p70S6K were phosphorylated at high level in patients with CML. Of note, treatment of CML cell line with rapamycin also resulted in a decrease of phosphorylation of 4E-BP1 and p70S6K. Consequently, rapamycin, the mTOR inhibitor, could decrease the phosphorylation of mTOR, and then downstream molecules of mTOR were also decreased because of a lower level of p-mTOR.

Some studies reported that mTOR inhibitor had impact on many molecules related with cell growth, cell cycle and angiogenesis, such as p21, cyclin D1, cyclin-dependent kinase 2, p27 and VEGF (21-24). The data presented here showed that rapamycin could induce cell cycle arrest and apoptosis interfering with proliferation and survival pathways in K562 cells. The cell viability in groups with rapamycin treatment displayed a significant decrease in a dose-dependent manner. We also presented increase of $G_{0} / G_{1}$ phase cells and decrease of $S$ phase cells after rapamycin treatment. These findings indicated that rapamycin, as the inhibitor of mTOR, blocked cell cycle progression from $\mathrm{G}_{1}$ to $\mathrm{S}$ phase via the inhibition of p70S6K and 4E-BP1, as reported previously $(25,26)$. Recent study also showed that rapamycin and the silencing of mTOR expression using siRNA resulted in increased apoptosis (26). Our study showed that treatment with $20 \mathrm{nmol} / 1$ or more rapamycin increased apoptotic cells, decreased expression of bcl-2 and activated caspase- 3 . The finding confirmed that rapamycin induced apoptosis in K562 cells.

In conclusion, the mTOR pathway might be involved in chronic myelogenous leukemia. Inhibition of the mTOR pathway interfers with cell proliferation and increase cell apoptosis in K562 cells. Our funding suggested that mTOR might be an important therapeutic target for myelogenous leukemia, especially patients with Bcr-Abl mutants who do not respond well to imatinib. Therefore, understanding of mTOR pathway should contribute to more efficient treatment for leukemia in the future.

\section{Acknowledgements}

This study was supported by Health Department of Hebei Province of China (No. 20090014 for Jie Li).

\section{References}

1. Kantarjian H, Sawyers C, Hochhaus A, et al: Hematologic and cytogenetic responses to imatinib mesylate in chronic myelogenous leukemia. N Engl J Med 346: 645-652, 2002.

2. O'Brien SG, Guilhot F, Larson RA, et al: Imatinib compared with interferon and low-dose cytarabine for newly diagnosed chronic-phase chronic myeloid leukemia. N Engl J Med 348: 994-1004, 2003.

3. Hess G, Meyer RG, Schuch B, Bechthold K, El-Kholy I and Huber C: Sustained remissions and low rate of BCR-ABL resistance mutations with imatinib treatment chronic myelogenous leukemia in patients treated in late chronic phase: a 5-year follow-up. Am J Hematol 83: 178-184, 2008.

4. Mancini M, Corradi V, Petta S, Martinelli G, Barbieri E and Santucci MA: mTOR inhibitor RAD001 (Everolimus) enhances the effects of imatinib in chronic myeloid leukemia by raising the nuclear expression of c-ABL protein. Leuk Res 34: 641-648, 2010.

5. Ly C, Arechiga AF, Melo JV, Walsh CM and Ong ST: Bcr-Abl kinase modulates the translation regulators ribosomal protein S6 and 4E-BP1 in chronic myelogenous leukemia cells via the mammalian target of rapamycin. Cancer Res 63: 5716-5722, 2003. 
6. Mohi MG, Boulton C, Gu TL, et al: Combination of rapamycin and protein tyrosine kinase (PTK) inhibitors for the treatment of leukemias caused by oncogenic PTKs. Proc Natl Acad Sci USA 101: 3130-3135, 2004.

7. Parmar S, Smith J, Sassano A, et al: Differential regulation of the p70 S6 kinase pathway by interferon alpha (IFNalpha) and imatinib mesylate (STI571) in chronic myelogenous leukemia cells. Blood 106: 2436-2443, 2005.

8. Foster KG and Fingar DC: Mammalian target of rapamycin (mTOR): conducting the cellular signaling symphony. J Biol Chem 285: 14071-14077, 2010.

9. Wang ZG, Fukazawa T, Nishikawa T, et al: RAD001 offers a therapeutic intervention through inhibition of mTOR as a potential strategy for esophageal cancer. Oncol Rep 23: 1167-1172, 2010.

10. Mishra R, Miyamoto M, Yoshioka T, et al: Adenovirus-mediated eukaryotic initiation factor $4 \mathrm{E}$ binding protein-1 in combination with rapamycin inhibits tumor growth of pancreatic ductal adenocarcinoma in vivo. Int J Oncol 34: 1231-1240, 2009.

11. Johnston PB, Inwards DJ, Colgan JP, et al: A Phase II trial of the oral mTOR inhibitor everolimus in relapsed Hodgkin lymphoma. Am J Hematol 85: 320-324, 2010.

12. Nagai T, Ohmine K, Fujiwara S, Uesawa M, Sakurai C and Ozawa K: Combination of tipifarnib and rapamycin synergistically inhibits the growth of leukemia cells and overcomes resistance to tipifarnib via alteration of cellular signaling pathways. Leuk Res 34: 1057-1063, 2010.

13. Abraham RT and Gibbons JJ: The mammalian target of rapamycin signaling pathway: twists and turns in the road to cancer therapy. Clin Cancer Res 13: 3109-3114, 2007.

14. Hirase C, Maeda Y, Takai S and Kanamaru A: Hypersensitivity of Ph-positive lymphoid cell lines to rapamycin: Possible clinical application of mTOR inhibitor. Leuk Res 33: 450-459, 2009.

15. Batista A, Barata JT, Raderschall E, Sallan SE, Carlesso N, Nadler LM and Cardoso AA: Targeting of active mTOR inhibits primary leukemia $\mathrm{T}$ cells and synergizes with cytotoxic drugs and signaling inhibitors. Exp Hematol 39: 457-472, 2011.

16. Weisberg E, Banerji L, Wright RD, et al: Potentiation of antileukemic therapies by the dual PI3K/PDK-1 inhibitor, BAG956: effects on BCR-ABL- and mutant FLT3-expressing cells. Blood 111: 3723-3734, 2008
17. Vivanco I and Sawyers CL: The phosphatidylinositol 3-kinase AKT pathway in human cancer. Nat Rev Cancer 2: 489-501, 2002.

18. Pyronnet S and Sonenberg N: Cell-cycle-dependent translational control. Curr Opin Genet Dev 11: 13-18, 2001.

19. Harada H, Andersen JS, Mann M, Terada N and Korsmeyer SJ: p70S6 kinase signals cell survival as well as growth, inactivating the pro-apoptotic molecule BAD. Proc Natl Acad Sci USA 98: 9666-9670, 2001

20. Meyuhas O: Synthesis of the translational apparatus is regulated at the translational level. Eur J Biochem 267: 6321-6330, 2000.

21. Yang J, Ikezoe T, Nishioka C, Ni L, Koeffler HP and Yokoyama A: Inhibition of mTORC1 by RAD001 (everolimus) potentiates the effects of 1,25-dihydroxyvitamin $\mathrm{D}(3)$ to induce growth arrest and differentiation of AML cells in vitro and in vivo. Exp Hematol 38: 666-676, 2010.

22. Yazbeck VY, Buglio D, Georgakis GV, et al: Temsirolimus downregulates p21 without altering cyclin D1 expression and induces autophagy and synergizes with vorinostat in mantle cell lymphoma. Exp Hematol 36: 443-450, 2008.

23. Mayerhofer M, Aichberger KJ, Florian S, et al: Identification of mTOR as a novel bifunctional target in chronic myeloid leukemia: dissection of growth-inhibitory and VEGF suppressive effects of rapamycin in leukemic cells. FASEB J 19: 960-962, 2005.

24. Mayerhofer M, Valent P, Sperr WR, Griffin JD and Sillaber C $\mathrm{BCR} / \mathrm{ABL}$ induces expression of vascular endothelial growth factor and its transcriptional activator, hypoxia inducible factor-1 $\alpha$, through a pathway involving phosphoinositide 3-kinase and the mammalian target of rapamycin. Blood 100: 3767-3775, 2002.

25. Gera JF, Mellinghoff IK, Shi Y, et al: AKT activity determines sensitivity to mammalian target of rapamycin (mTOR) inhibitors by regulating cyclin D1 and c-myc expression. J Biol Chem 279: 2737-2746, 2004

26. Vega F, Medeiros LJ, Leventaki V, et al: Activation of mammalian target of rapamycin signaling pathway contributes to tumor cell survival in anaplastic lymphoma kinase-positive anaplastic large cell lymphoma. Cancer Res 66: 6589-6597, 2006. 